Reprinted from RADIATION RESEARCH, Volume 14, No. 2, February 1961

Copyright @ 1961 by Academic Press Inc. Printed in U.S.A.

RADIATION RESEARCH 14, 213-222 (1961)

\title{
A Direct Measurement of the Radiation Sensitivity of Normal Mouse Bone Marrow Cells ${ }^{1}$
}

\author{
J. E. TILL AND E. A. McCULLOCH \\ Department of Medical Biophysics, University of Toronto, and the Divisions of \\ Biological Research and Physics of the Ontario Cancer Institute, \\ Toronto, Ontario
}

\section{INTRODUCTION}

Evidence is accumulating that the proliferative capacity of mammalian cells has a uniformly high radiation sensitivity regardless of the species and tissue of origin. The evidence derives from experiments on fresh explants and established cell lines in tissue culture (1-4), and on transplantable tumors in vivo (5) where single-cell techniques have been applied. Further, experiments using an indirect technique to measure the sensitivity of normal mouse bone marrow indicated that these cells have a radiation sensitivity of similar magnitude (6). In the present report a direct method of assay for these cells with a single-cell technique will be described.

The method is based on the fact that the intravenous injection of an appropriate number of marrow cells into isologous hosts previously exposed to supralethal total-body irradiation leads to the formation of colonies of proliferating cells in the spleens of these animals. These colonies appear as gross nodules in the spleen, which may readily be counted. The relationship between the number of cells injected and the number of colonies appearing in the spleen has been determined and used to study the sensitivity to radiation of the proliferative capacity in vivo of normal adult mouse bone marrow cells irradiated in vitro. The results show that normal mouse bone marrow cells have a similar radiation sensitivity to other mammalian cells tested by very different methods.

Mice

EXPERIMENTAL PROCEDURES

Eight- to twelve-week-old $\mathrm{C}_{57} \mathrm{Bl} / \mathrm{Ha}$ and $\mathrm{C}_{3} \mathrm{Hf} / \mathrm{Ha}$ mice bred in this laboratory were used in the experiments. Each experimental group consisted of 25 mice, with approximately equal numbers of males and females. After irradiation and injection

${ }^{1}$ The research for this paper was supported (in part) by the Defence Research Board of Canada, under Grant DRB 9350-14 (G and C) and (in part) by the National Cancer Institute of Canada. 
of marrow they were housed 3 to 4 animals per cage and allowed food (Ralston Purina Mills mouse diet) and water as desired.

\section{Preparation and Injection of Marrow Suspensions}

Marrow cells were obtained from the femora of normal mice, suspended in Puck's saline $\mathrm{A}$, and the nucleated cells were counted in a hemacytometer as previously described (6). Microscopic examination showed the suspension to consist predominantly of single isolated cells with very few visible clumps of cells. Suspensions containing the number of cells required for each experimental group were prepared by serial dilutions. These suspensions were kept at ice-water temperature until they were injected.

\section{Irradiation Procedures}

Marrow cell suspensions to be irradiated were placed in stoppered 12-ml polyethylene tubes. The tubes were agitated immediately before irradiation to ensure that the cells were in suspension and adequately aerated. The tubes were placed in a Lucite sample holder having a wall thickness of $5 \mathrm{~mm}$, in a fixed position $22 \mathrm{~cm}$ below a cobalt-60 radiation source. The absorbed dose rate at the sample was 330 rads/min. Dosimetry was based on air ionization measurements made with a Victoreen condenser chamber calibrated by the U. S. National Bureau of Standards and by the National Research Council of Canada.

The recipient mice were irradiated during the afternoon of the day prior to the injection of the marrow cells. Irradiation of the mice was carried out as previously described (6). The absorbed dose in the soft tissues of the recipient mice was 950 rads.

As soon as possible after irradiation of the marrow suspensions, $0.5-\mathrm{ml}$ aliquots were injected intravenously into preirradiated recipient mice.

\section{Enumeration of Colonies in the Spleens of Irradiated Recipient Mice}

The irradiated recipient mice were observed for 10 to 11 days. During this period a proportion of the mice died. Survivors were killed on the tenth or eleventh day, and their spleens examined. The spleens of animals that had received from $10^{4}$ to $10^{5}$ nucleated unirradiated cells contained discrete nodules, which were counted. The spleens were then fixed in formalin, and histological sections stained with hematoxylin and eosin were prepared. ${ }^{2}$

\section{RESULTS}

\section{Morphology of the Nodules in the Spleen}

The nodules observed in the spleens of the irradiated recipient mice 10 days after injection are discrete, round or oval, gray in colour, and embedded in the

\footnotetext{
${ }^{2}$ After submission of this paper, it was found that fixation of spleens with nodules in Bouin's solution made the nodules more distinct, increasing the ease with which they could be counted.
} 
red mass of the spleen (Fig. 1). Histological examination reveals that they consist of colonies of rapidly proliferating hematopoietic tissue. Although many of the cells are too undifferentiated to allow identification, large numbers of early and late erythroblasts are present, and smaller numbers of myelocytes and metamyelo-

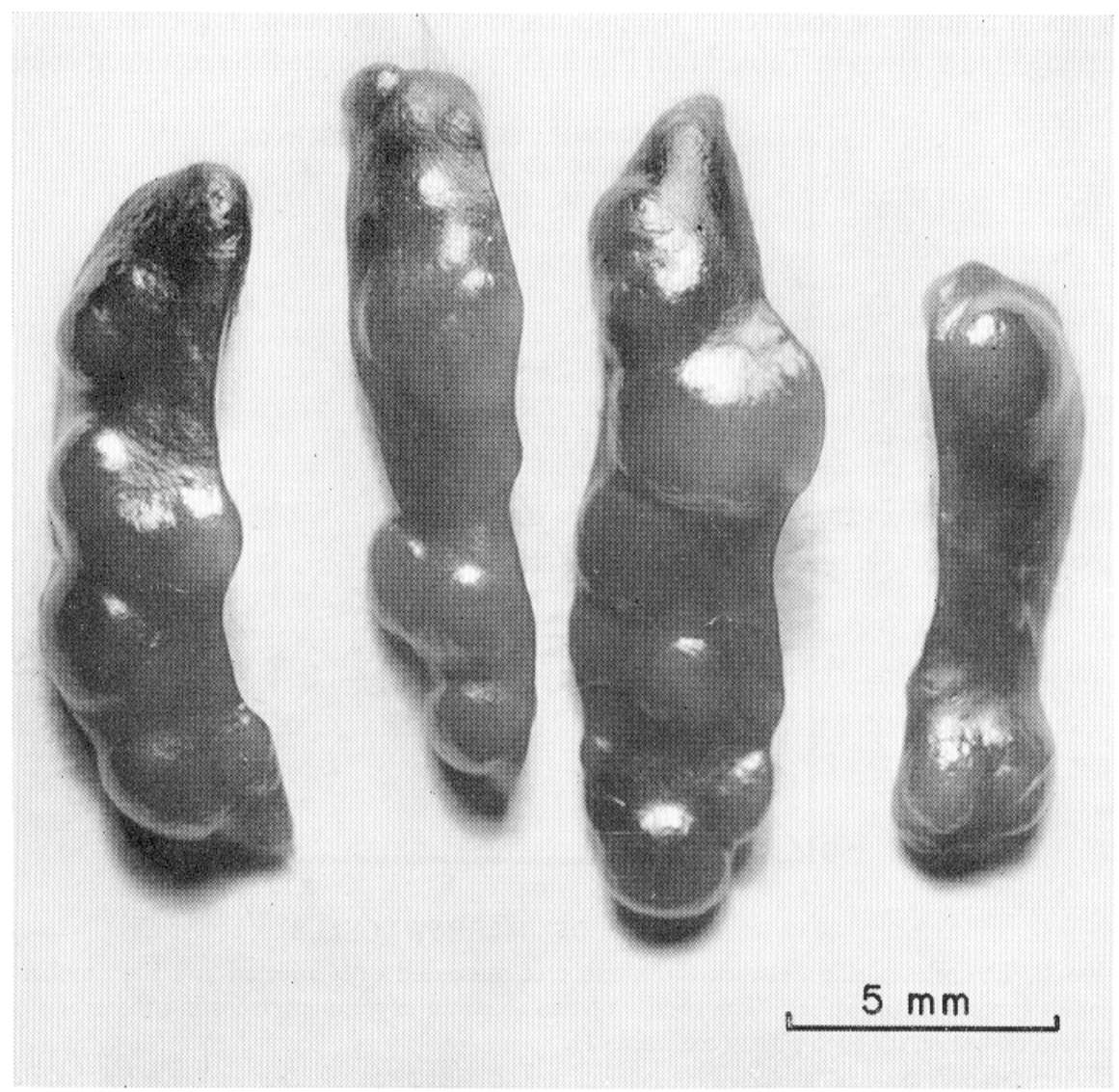

FIG. 1. Spleens of irradiated mice 10 days after injection of $6 \mathrm{X} \mathrm{IO}^{4}$ nucleated cells. The nodules on which the assay is based are readily seen.

cytes can be recognized. The differentiated cells are usually grouped together within the nodule. The erythroblasts are frequently more obvious in the center of the nodule, and the myeloid cells at the periphery. The process of differentiation is more marked if the spleens are taken 11 days after transplantation. In these nodules granulopoiesis and erythropoiesis are equally well advanced, and in many of the nodules clusters of four to five megakaryocytes can be easily identified. 
The Relationship between the Number of Nodules in the Spleen and the Number of Nucleated Marrow Cells Administered

The nodules observed in the spleens are colonies of cells resulting from the proliferation of viable cells of the marrow graft. The spleens of irradiated animals not receiving an injection of marrow cells showed no nodules. The relationship between the mean number of colonies in the spleens and the number of nucleated marrow cells injected is given in Table I and Fig. 2. In Table I are listed the results of colony

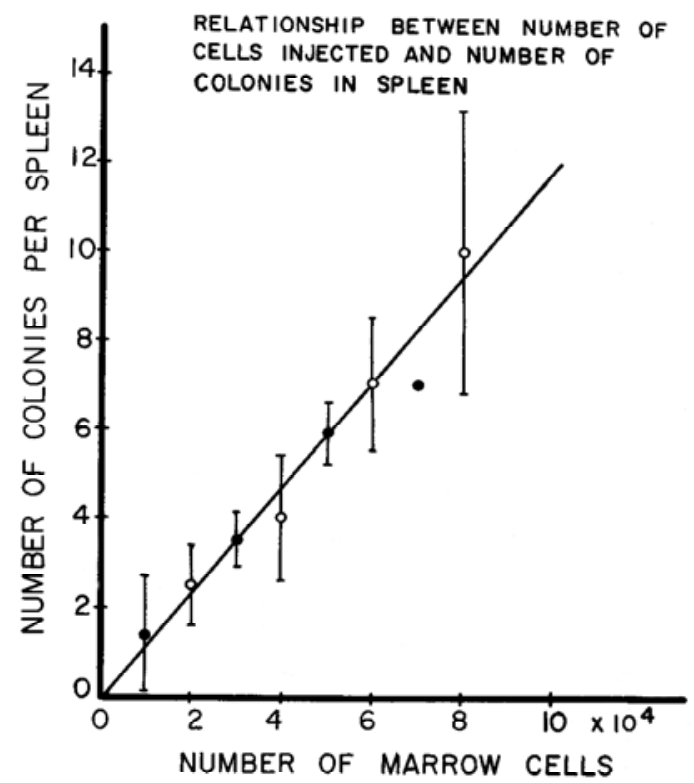

FIG. 2. The relationship between the number of nucleated cells injected and the number of colonies formed in the spleen. The results of two separate experiments showing the mean and standard deviation for each point (see Table 1).

counts from the spleens of animals injected with different numbers of marrow cells. A separately prepared marrow suspension was used in each experiment. The data of Table I are graphed in Fig. 2. A least-squares straight line has been drawn through the two sets of results. Statistical analysis shows that the data do not deviate significantly from linearity, nor is the intercept significantly different from zero $(\mathrm{P}>0.5)$. The results are thus compatible with the assumption that single viable cells from the marrow graft are able to give rise to colonies in the spleen. However, this assumption has by no means been proved. In view of this, and because the marrow suspensions injected contain many different cell types, the identity of the cells giving rise to colonies is uncertain. Owing to this uncertainty, we 
will refer to cells with the capacity to form colonies as "colony-forming units" (CFU).

A given marrow preparation may be characterized by the number of CFU per $10^{5}$ cells injected. The last column of Table I gives this quantity, which was cal-

TABLE I

The Relationship Between the Number of Nucleated Marrow Cells InJeCted AND the NUMBER OF COLONI[ES FORMED IN THE SPLEENS OF IRRADIATED $\mathrm{C}_{57} \mathrm{Bl}$ MICE

$$
\begin{gathered}
\text { N,umber of } \\
\text { Experi- marrow cells } \\
\text { ment injected, } \\
\quad \times 10^{-4}
\end{gathered}
$$$$
\text { Spleen colony counts }
$$

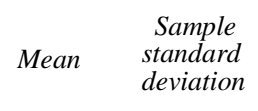

CFU per $10^{5}$

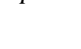

1

1.0
3.0
5.0
7.0

$3,0,0,2,2$

$1.4 \quad 1.3$

$3,4,4,3$

$6,5,6,6,6,5,7$

3.5

5.9

0.7

--

$11.2 \pm 0.5$

$2 \quad 2.0$

3, 3, 1, 3

$2 . .5 \quad 1.0$

4.0

2, 2, 5, 4, 5, 4, 6, 5, 3

4.0

1.4

6.0

$6,7,10,5,7,7,7$

7.0

7, 11, 15, 8, 9

10.0

1.5 .

3.2

$11.7 \pm 0.7$

${ }^{\mathrm{a}}$ A linear relationship is assumed (see Fig. 2).

TABLE II

CONCENTRATION OF COLONY-FORMING UNITS (CFU) IN VARIOUS

Preparations of Normal Adult Mouse Bone Marrow

$$
\begin{aligned}
& \text { Strain } \\
& \\
& \mathrm{C}_{57} \mathrm{Bl} \\
& \mathrm{C}_{57} \mathrm{Bl} \\
& \mathrm{C}_{57} \mathrm{Bl} \\
& \mathrm{C}_{57} \mathrm{Bl} \\
& \mathrm{C}_{3} \mathrm{H} \\
& \mathrm{C}_{3} \mathrm{H} \\
& \mathrm{AKN}
\end{aligned}
$$$$
\text { CFU per } 10^{\mathrm{b}} \text { nucleated cells }{ }^{\mathrm{d}}
$$

$$
\begin{aligned}
11.2 & \pm 0.5^{*} \\
11.7 & \pm 0.7 * \\
8.1 & \pm 0.5 \\
8.0 & \pm 1.0 \\
7.5 & \pm 1.6 \\
9.4 & \pm 5.5 \\
12 &
\end{aligned}
$$

\footnotetext{
a Table values marked with an asterisk $(*)$ were taken from Table 1. Each of the remaining values was obtained from a single concentration of marrow cells.
}

culated by the method of least squares, on the assumption that the relationship between the number of marrow cells injected and the number of colonies formed in the spleen was a straight line through the origin, as depicted in Fig. 2. Though these two marrow preparations contained a similar number of CFU per $10^{5}$ cells, this was not always the case. Equal numbers of nucleated cells from different marrow preparations may contain different numbers of CFU. Table II lists the 
number of CFU per $10^{5}$ cells for several separate marrow preparations. Though it is apparent that there is no important difference between preparations from $\mathrm{C}_{57} \mathrm{Bl}$, $\mathrm{C}_{3} \mathrm{H}$, or $\mathrm{AKN}$ mice, the results indicate that the relation between nucleated cells

TABLE III

Survival of Colony-Forming Units (CFU) IN $\mathrm{C}_{57}$ Bl MARRow SUSPENSIONS IRRADIATED WITH $\mathrm{Co}^{60}$ GAMMA-RAYS

\begin{tabular}{|c|c|c|c|c|c|c|c|}
\hline Radiation dose (rads) & 0 & 96 & 192 & 288 & 432 & 576 & 672 \\
\hline $\begin{array}{l}\text { Nucleated cells } \\
\text { injected, X } 10^{-5 a}\end{array}$ & 1.25 & 1.75 & 3.0 & 7.2 & 24 & 75 & 120 \\
\hline Number of mice injected & 25 & 25 & 25 & 25 & 25 & 25 & 25 \\
\hline $\begin{array}{l}\text { Number of mice alive after } \\
10 \text { days }\end{array}$ & 6 & 7 & 4 & 9 & 11 & 15 & 4 \\
\hline $\begin{array}{l}\text { Spleen colony counts } \\
\text { (CFU) }\end{array}$ & $\begin{array}{c}11 \\
10 \\
11 \\
11 \\
9 \\
8\end{array}$ & $\begin{array}{r}12 \\
8 \\
9 \\
9 \\
8 \\
9 \\
11\end{array}$ & $\begin{array}{l}11 \\
10 \\
11 \\
14\end{array}$ & $\begin{array}{r}8 \\
8 \\
9 \\
12 \\
6 \\
10 \\
13 \\
10 \\
6\end{array}$ & $\begin{array}{r}12 \\
12 \\
14 \\
10 \\
7 \\
10 \\
8 \\
11 \\
8 \\
7 \\
6\end{array}$ & $\begin{array}{r}7 \\
5 \\
9 \\
4 \\
9 \\
10 \\
7 \\
8 \\
9 \\
7 \\
12 \\
7 \\
11 \\
7 \\
11\end{array}$ & $\begin{array}{l}2 \\
3 \\
3 \\
4\end{array}$ \\
\hline Mean CFU & 10.0 & 9.4 & 11.5 & 9.1 & 9.6 & 8.2 & 3.0 \\
\hline CFU per $10^{\circ}$ cells & 8.0 & 5.4 & 3.8 & 1.25 & 0.40 & 0.11 & 0.025 \\
\hline Fraction surviving & 1.00 & 0.67 & 0.48 & 0.16 & 0.050 & 0.014 & 0.0031 \\
\hline
\end{tabular}

${ }^{\text {a }}$ At each radiation dose level, the number of cells injected was adjusted to compensate for the decrease in CFU that occurs as the radiation dose is increased.

and CFU is sufficiently variable to make the nucleated cell count unreliable without a measurement of CFU.

The Radiation Survival Curve for Mouse Bone Marrow Cells, Obtained by Spleen Colony Counts

In vitro irradiation of aliquots of a given marrow suspension with $\mathrm{Co}^{6 \mathrm{O}} \gamma$-rays was found to reduce the number of CFU per $10^{5}$ nucleated cells. The results of an 
experiment are presented in Table III. As may be seen from the second column of the table, in the control group of 25 mice, 6 mice were alive at 10 days, and the mean number of colonies in the spleens of these animals was found to be 10.0. Since

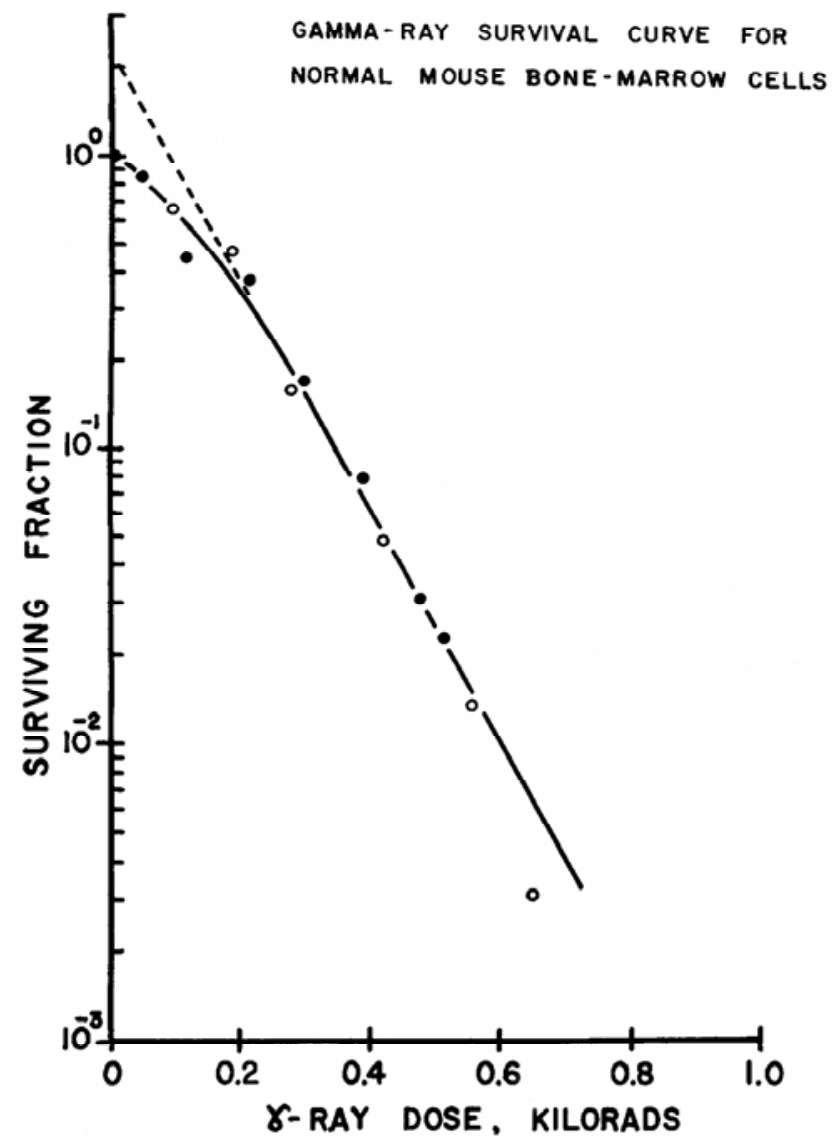

FIG. 3. X-Ray survival curve for normal mouse bone marrow cells. Closed circles are results obtained with strain $\mathrm{C} 3 \mathrm{H}$, and open circles are results obtained with strain $\mathrm{C}_{57} \mathrm{BI}$. The extrapolation of the straight portion of the curve to zero dose is shown as a dotted line.

each animal was injected with $1.25 \times 10^{5}$ nucleated marrow cells, this particular marrow suspension had $8.0 \mathrm{CFU}$ per $10^{5}$ cells. The results listed in the next column of Table III show that the same marrow suspension, after irradiation with 96 rads, contained only $5.4 \mathrm{CFU}$ per $10^{5}$ cells, or a fractional survival of 0.67 of the control value. The decrease in the number of CFU per $10^{5}$ cells with increasing radiation 
dose can be plotted as a survival curve, as shown in Fig. 3. The points plotted as open circles in Fig. 3 are the results obtained with $\mathrm{C}_{57} \mathrm{Bl}$ mice, shown in the last line of Table III. The closed circles are the results of an experiment performed in the same manner, but with strain $\mathrm{C}_{3} \mathrm{H}$ mice. It is apparent that experiments performed on these two strains yield similar results.

The two sets of points were best fitted with a sigmoid-like curve which was found to have a $\mathrm{D}_{0}$ of $115 \pm 8$ rads and an extrapolation number, or hit number, of about 2 . The $\mathrm{D}_{0}$ represents the dose required to reduce the surviving fraction by a factor of 0.37 , on the exponential portion of the curve. The extrapolation number was obtained by extrapolating the exponential portion of the curve back to zero dose and reading off the ordinate. The best-fit curve was obtained by subjecting the ordinate values to a complementary log-log transformation (7). The resulting values were approximately linear with dose and were fitted with a straight line by the method of least squares.

\section{Histological Appearance of Colonies from Irradiated Suspensions}

The spleens of all the animals used in the experiments to determine the survival curve (Fig. 3) were examined histologically. In every nodule, cells sufficiently mature to be identified could be seen with ease, indicating that differentiation was proceeding. Further, in the nodules arising from the irradiated suspensions no feature was seen that could be used to distinguish them from the nodules arising from control suspensions. Thus, cells in the irradiated suspensions that retained the ability to form colonies also retained the ability to supply populations of differentiated cells.

\section{DISCUSSION}

The method described in this paper for determining the number of viable cells in a suspension of mouse bone marrow has similarities with the tissue culture techniques of clone counting first described by Puck and Marcus (8). In each, a small number of cells is inoculated. In each, discrete colonies are formed and counted. From this point of view, the irradiated mouse may be considered as providing the receptacle, the medium, and control of temperature, $\mathrm{pH}$, and humidity required for the cultivation of marrow cells. In tissue culture, the one-to-one correspondence between the number of cells inoculated and the number of colonies counted provides overwhelming evidence that most of the colonies are clones. In our animal experiments, a one-to-one correspondence between cells injected and colonies counted was not obtained; indeed about $10^{4}$ cells had to be injected to give rise to a single colony in the spleen. However, in counting the number of cells in the marrow suspension, all nucleated cells are counted. A high proportion of these are differentiated and presumably unable to give rise to a new generation of primitive cells. Further, only cells arriving at the spleen, and not cells that settle in the marrow, can be counted. Thus, only a proportion of the viable primitive cells 
gives rise to the colonies that are counted. These considerations make it likely that each colony derives from a very small number of cells and possibly from one cell. The results of the X-ray experiments, which showed a curve with form similar to the curves obtained for single cells measured in tissue culture, lends further support to the possibility of a clonal origin of the colonies.

In the experiments reported here, the spleen colony-counting method has been used to study the radiation sensitivity of the proliferative capacity of marrow cells, but it is also applicable to any problem in which a measure of the number of viable cells in a suspension of marrow is required. The variability found in the numbers of CFU in different marrow suspensions (Table II) indicates the need for such a measure.

The in vivo system has an advantage over the measurement of colonies in vitro because the cells in the animal not only multiply but also differentiate, and the pattern of differentiation provides another criterion by which cell behavior can be judged. When this criterion was applied to the irradiated cell suspensions, it was clear that cells capable of continued proliferation were also capable of differentiation.

The results of the radiation experiments yielded a $\mathrm{D}_{0}$ of $115 \pm 8$ rads of $\mathrm{Co}^{60} \gamma$ rays for normal mouse bone marrow cells, irradiated in vitro, but proliferating in vivo. This $\mathrm{D}_{0}$ agrees very well with the value of $105 \pm 24$ rads of 280-kvp X-rays, determined with less precision by an earlier method (6). The $\mathrm{D}_{0}$ for normal mouse bone marrow cells in vivo is thus similar in magnitude to the $\mathrm{D}_{0}$ of 165 rads of $\mathrm{Co}^{60}$ $\gamma$-rays reported for lymphoma cells in vivo (5) and to that for normal and malignant human cells in tissue culture (1), whose $\mathrm{D}_{0}$ lies between 100 and 150 rads of 230kvp X-rays.

The agreement between these results obtained for cells growing in vivo with those obtained for cells in vitro implies that results obtained by in vitro methods give information that can be extrapolated to the in vivo situation with some confidence. Further, the evidence presented here supports the suggestion that the radiation sensitivity of mammalian cells is not strongly dependent on species and tissue of origin.

\section{SUMMARY}

1. A direct technique for the measurement of the number of cells in a bone marrow suspension capable of continued proliferation is described.

2. The technique was used to measure the radiation sensitivity of normal mouse bone marrow cells and yielded a $\mathrm{D}_{0}$ of $115 \pm 8$ rads.

\section{ACKNOWLEDGMENTS}

The authors wish to thank Mr. James Hicks, Miss Rosemary Wyncoll, and Miss Heidi Voss for their excellent technical assistance.

RECEIVED: July 28, 1960 


\section{REFERENCES}

1. T. T. Puck, D. Morkovin, P. 1. Marcus, and S. J. Cieciura, Action of X-rays on mammalian cells. II Survival curves of cells from normal human tissues. J. Exptl. Med. 106, 485-500 (1957).

2. M. M. ElKIND and, H. SutTon, X-ray damage and recovery in mammalian cells in culture. Nature 184, 1293-1295 (1959).

3. J. E. Till, C. P. Stanners, S. Gulyas, and G. F. Whitmore, Nucleic acid synthesis and the mitotic cycle in X-irradiated L-strain mouse cells. To be published.

4. T. T. PucK, Quantitative studies on mammalian cells in vitro. Rev. Modern Phys. 31, 433- 448 (1959).

5. H. B. HEWITt and C. W. WILSON, A survival curve for mammalian leukaemia cells irradiated in vivo (implications for the treatment of mouse leukaemia by whole-body irradiation). Brit. J. Cancer 13, 69-75 (1959).

6. E. A. McCulloch and J. E. Till, The radiation sensitivity of normal mouse bone marrow cells, determined by quantitative marrow transplantation into irradiated mice. Radiation Research 13, 115--125 (1960).

7. R. A. FIsher and F. Yates, Statistical Tables for Biological, Agricultural and Medical Research, 5th ed., Hafner Publishing Co., New York, 1957.

8. T. T. PuCK and P. 1. MArcus, Action of X-rays on mammalian cells. J. Exptl. Med. 103, 653- 666 (1956). 